\title{
Determinants of sporadic Campylobacter infections in Denmark: a nationwide case-control study among children and young adults
}

This article was published in the following Dove Press journal:

Clinical Epidemiology

\author{
Katrin Gaardbo Kuhn' \\ Eva Møller Nielsen² \\ Kåre Mølbak',3 \\ Steen Ethelberg'
}

'Infectious Disease Epidemiology \& Prevention, Statens Serum Institut, Copenhagen, Denmark; ${ }^{2}$ Bacteria, Parasites \& Fungi, Statens Serum Institut, Copenhagen, Denmark; ${ }^{3}$ Institute of Veterinary and Animal Sciences, University of Copenhagen, Copenhagen, Denmark
Correspondence: Katrin Gaardbo Kuhn Infectious Disease Epidemiology \& Prevention, Statens Serum Institut, Artillerivej 5, DK-2300 Copenhagen S, Denmark

Tel +4532688183

Email kuh@ssi.dk
Background: Each year more than 4,000 cases of campylobacteriosis are reported in Denmark, making it the most common bacterial gastrointestinal infection. Here we describe a case-control study to identify sources of infection with a focus on environmental factors.

Methods: From January to December 2016, we conducted a prospective case-control study among Danish persons aged 1-30 years. Participants were invited by letter to complete an online questionnaire. Crude and adjusted ORs were calculated and final parsimonious multivariate models developed using logistic regression.

Results: The study recruited 1366 cases and 4,418 controls, of whom $65 \%$ and $66 \%$, respectively, completed the questionnaire. A multivariate model for domestically acquired cases showed, among others, increased risk of infection with bathing in fresh water $(\mathrm{OR}=5.1)$, contact to beach sand $(\mathrm{OR}=1.8)$, owning a pet $\operatorname{dog}$ with diarrhea $(\mathrm{OR}=4.6)$, and eating minced beef $(\mathrm{OR}=2.6)$ or chicken $(\mathrm{OR}=2.5)$. The model for children highlighted similar risk factors but also included bathing in a paddling pool $(\mathrm{OR}=13.6)$ and eating fresh strawberries $(\mathrm{OR}=5.3)$. A separate analysis for persons reporting foreign travel showed increased infection risk when traveling to Asia, Africa, or Turkey and that eating from street kitchens and having contact to water during traveling were also risk factors. Conclusion: Environmental factors and animal contact account for a sizeable proportion of domestic Campylobacter infections in the age group studied. The study also re-confirmed handling/consumption of chicken as an important risk factor while highlighting minced beef as a potential new risk factor. Overall, these results contribute to a better understanding of the transmission dynamics of Campylobacter and will be used to improve national guidelines for prevention of infection.

Keywords: Campylobacter, determinants, case-control, environment, food

\section{Introduction}

Campylobacter spp. are a global cause of gastroenteritis in humans, particularly in industrialized countries. In Denmark, incidences have increased since 2012 and campylobacteriosis is now the most frequently reported gastrointestinal infection ${ }^{1}$ with 4,243 reported cases in 2017 , corresponding to 73.7 cases per 100,000 population. This pattern is repeated throughout Europe, Australia, and the US where incidences remain high and have even increased during the past decade. ${ }^{2-4}$ Campylobacteriosis is a zoonotic disease with poultry, wild birds, and domestic pets as the main reservoirs. . $^{5}$ Symptoms in humans manifest as acute watery or bloody diarrhea and treatment is usually only required for severe cases or if infection triggers Guillain-Barré syndrome. Infection occurs in all age groups but incidences are higher in young persons, particularly children younger than 5 years. ${ }^{1,7}$ This age pattern of infection is most likely 
influenced by acquired immunity; children are repeatedly exposed to Campylobacter, through food and the immediate environment, developing partial immunity which allows them to remain asymptomatic (following most exposures) if infected as adults. ${ }^{8}$

Campylobacteriosis is a mainly sporadic disease. When outbreaks occur, they have often been linked to contaminated water, raw (unpasteurized) milk, animal contact, and environmental exposures such as mud and sand. ${ }^{9-14}$ In Denmark, recent evidence from next-generation sequencing suggests that case clustering - and even outbreaks - may be more common than assumed. ${ }^{15}$ To identify risk factors for sporadic cases, three Danish $^{16-18}$ and numerous foreign case-control studies have been undertaken. ${ }^{19-26}$ These consistently identified traveling abroad, poor handling, and/or consumption of raw or undercooked chicken, consumption of raw milk, and animal contact as important determinants of infection, but a large proportion of cases remained unexplained. The current gray areas of Campylobacter epidemiology in particular cover the true spectrum of risk factors and the relative importance of poultry in relation to other exposures. ${ }^{27-29}$ Further, most case-control studies included persons of all ages which, considering the agerelated partial immunity, may introduce bias as they are not all at equal risk of developing disease. ${ }^{30}$ In other words, including controls from older age groups are likely to underestimate the importance of some risk factors and potentially miss others.

In this paper, we describe a national case-control study on Campylobacter risk factors in Denmark undertaken to identify the most important sources of infection, focusing on possible non-food determinants. To reduce the potential bias caused by partial immunity, we included only persons aged 1-30 years which also covers individuals believed to be at highest risk of disease.

\section{Methods}

\section{Study design and population}

The study was a national prospective case-control frequencymatched study with a population representative control group, conducted over a 12-month period beginning in January 2016. The total population of Denmark at that time was 5,700,000, of which 2,100,000 (37\%) persons were aged between 1 and 30 years. Based on historical notification data, we expected approximately 1,300 cases to be reported in this age group during the study period.

\section{Cases}

A case was a person with a confirmed Campylobacter infection (all species), diagnosed using either culture, polymerase chain reaction, or serology, who was aged older than 1 and younger than 31 years and who lived in Denmark at the time of diagnosis. Cases were excluded in two steps: firstly from being invited to participate and secondly from being included in the analysis. The first exclusion step included cases who: 1) did not have a valid Danish address, 2) had their address and/or name protected by law, 3) were aged under 18 years and did not live with either parent, or 4) were not alive at the time of invitation. In the second step, we excluded cases who did not coherently answer the questionnaire. New cases were identified on a weekly basis through the national case notification register based on extraction of data from the Danish Microbiology Database $(\mathrm{MiBa})^{31}$ and assessed for inclusion using the criteria presented above. Each notification contains as a minimum information on name, age, gender, date of sample received in the laboratory, and the unique personal Civil Registry System (CPR) number. The CPR allows identification of the person's address and familial status (eg, name and address of parents).

\section{Controls}

In total, 5,102 population controls aged 1-30 years living in Denmark were randomly extracted from the CPR System at the beginning of the study. From this group, a random sample of controls was selected for participation in the study each month. To account for the seasonal variation of campylobacteriosis, the number of controls asked for participation in any given month was correlated to the expected number of cases in that month (resulting in approximately four times more controls than cases each month).

Controls were also excluded in two steps. Firstly for the same reasons as for cases and if they resided in the same household as a previously included control. Secondly, controls who reported symptoms of gastrointestinal illness (diarrhea [bloody or non-bloody] and/or vomiting) during the past month and who did not coherently complete the questionnaire were excluded.

\section{Recruitment and questionnaire}

We recruited all cases and controls using a postal letterbased invitation, containing a rationale for the study, a short description of the questionnaire, and a personalized link (including username and password) to an online questionnaire. At the same webpage, invitees could decline participating in the study. For persons younger than 18 years, the invitation was sent to a parent living at the same address (the mother as a default). Parents completing questionnaires on behalf of children aged 12-17 were encouraged to answer 
the questions along with the child. Before recruitment, the vital status of each participant and - for persons under 18 years of age - their parents was assessed through the CPR System. Two postal reminders were sent 7 and 14 days, respectively, after the initial invitation to persons who had not completed the questionnaire and who had not actively declined to participate.

The questionnaire collected information on a range of exposures in the 5 days prior to symptom onset (cases) or the 5 days prior to completion of the questionnaire (controls) and as habits/baseline. Exposures included medical history, demographic information, overseas travel, recreational activities, dining locations, food and drink, kitchen hygiene, and animal contact. Questions on medical history and use of medication were asked based on a 4-week history and questions on travel on a 14-day history. Cases and controls reporting travel abroad provided further information about their journey, including exposures, after which they were excluded from the rest of the questionnaire. Participants could access their questionnaire at any time, save completed parts, and return at a later point. Passwords and usernames were valid for 8 weeks.

\section{Seasonality}

Because campylobacteriosis is highly seasonal in Denmark and exposures relating to the environment in particular are dependent on season, a season variable was included as a confounder. For cases, this variable was the month of selfreported symptom onset or, if they did not provide a symptom onset, the month when their sample was received in the laboratory. For controls, the season variable was defined as the month in which their questionnaire was completed (as they provided answers relating to their activities immediately prior to completing the questionnaire rather than at the time of inclusion in the study).

\section{Data analysis}

We performed univariate analyses on all explanatory variables to generate crude and adjusted odds ratios (ORs) with $95 \%$ confidence intervals (CIs). Multivariate analyses were performed by backward stepwise logistic regression modeling with elimination of nonsignificant variables based on the model deviance statistics and $P$-values. Two models were constructed: one for all participants in the study (ages 1-30 years) and one for small children (ages 1-5 years). Potential confounders were selected based on knowledge of determinants for Campylobacter infection $^{1}$ and included age, sex, residential area (urban or rural), and season (as described above). Adjustments were made for these potential confounders and for two-factor interactions identified from investigative analysis of all explanatory variables.

Population attributable fractions (PAFs) were calculated using adjusted ORs from the final logistic regression models for each explanatory variable associated with an increased risk of infection.

All data were analyzed using STATA version 14 (Stata Corp, College Station, TX, USA).

\section{Results \\ Study population}

During 2016 in Denmark, 1,538 cases of Campylobacter were reported among persons aged 1-30 years. After exclusions (Figure 1), we invited 1,527 of these (99.3\%) to participate. A total of 161 cases $(11 \%)$ returned the invitation letter to sender and were excluded from the study. Of the remaining 1,366 cases, 887 (65\%) responded to the questionnaire, resulting in 556 cases available for the domestic risk factor analysis and 309 cases for the travel risk factor analysis (Figure 1). Of the 5,102 randomly selected controls, 4,808 were eligible for invitation (Figure 1). In total, 390 (8\%) of these returned the invitation letter to sender and 4,418 controls therefore had a possibility to fill in the questionnaire. Of these, 2,935 (66\%) persons responded, and this resulted in 2,117 controls for the domestic risk factor analysis and 298 for the travel risk factor analysis (Figure 1).

There was no significant difference between cases and controls with respect to the distribution of gender, residential area, and - for persons older than 18 - occupation status (working/studying or unemployed). However, there were proportionally more cases than controls in the age group 1-4 years and more controls than cases in the age groups 5-9 and 10-14 years (Table 1 ).

\section{Univariate analysis of risk factors Travel abroad}

Traveling abroad was the single most important risk factor for infection for all cases $(\mathrm{OR}=4.6,95 \%$ CI 3.7-5.7). Participants had traveled to 68 different countries with 29 countries (43\%) being represented with a frequency of more than five visits. Cases exhibited a greater variation in the number of countries visited; 62 (91\%) of the listed countries were visited by at least one case while for controls this was 37 (54\%) countries. Risk of infection was higher for visitors to Asian countries and Turkey, whereas visiting Northern Europe and Scandinavia was associated with a reduced risk of infection (Table 2). For travelers, staying in a Bed \& Breakfast (compared to all other types of accommodation, including outdoor camping), 


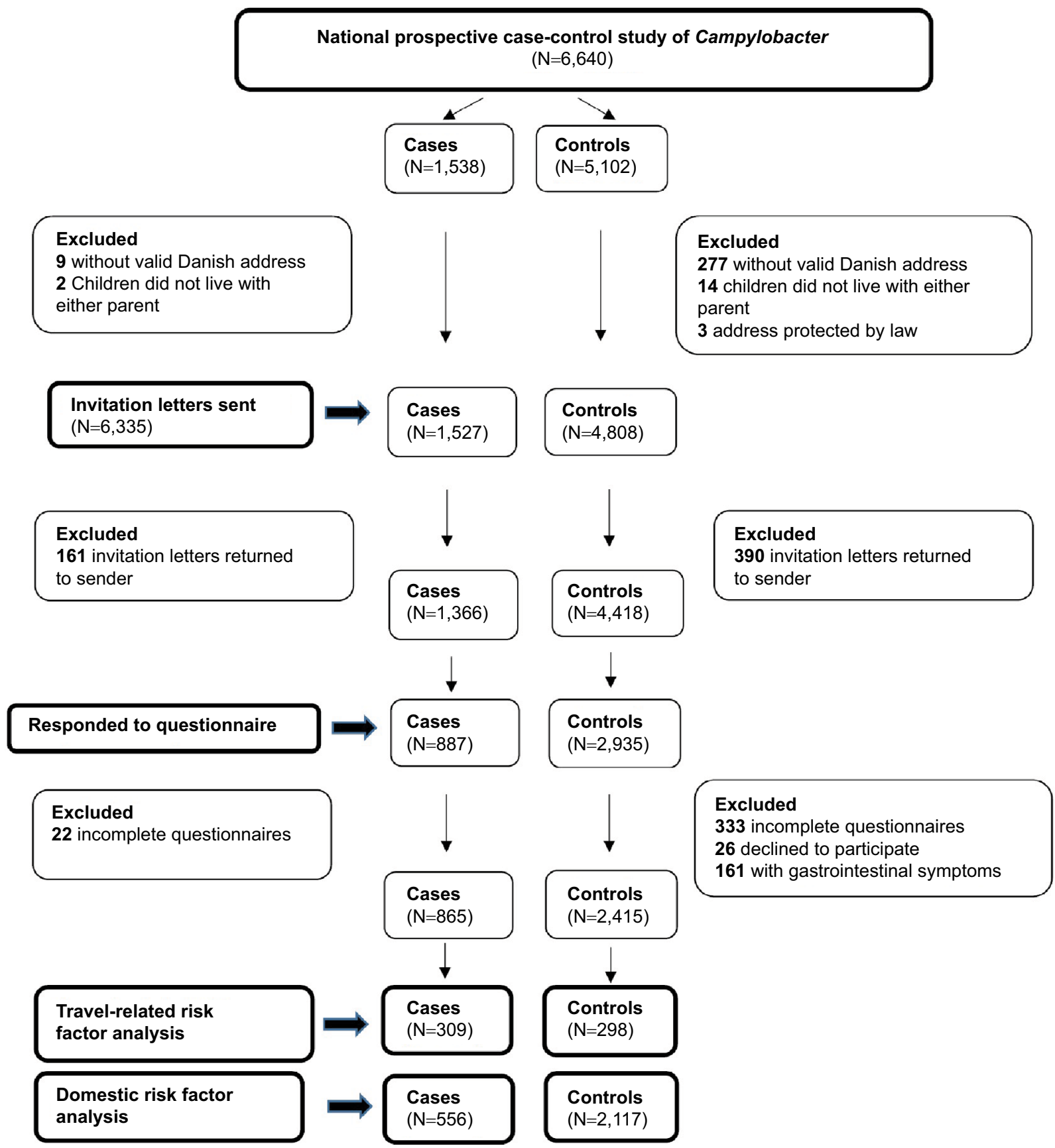

Figure I Participant flow chart.

consuming food from street kitchens, having contact to sand, soil, and/or mud, and bathing in sea water carried an increased risk of infection, whereas cooking one's own food was inversely associated with campylobacteriosis (Table 2).

All subjects reporting travel abroad were excluded from the risk factor analysis for domestic factors presented below.

\section{Environmental exposures}

Contact to water from natural sources was associated with infection. Specifically, cases were more likely to have bathed in sea- or freshwater or in a paddling pool and have consumed water from a stream or spring in nature (Table 3). There was also a higher risk of infection associated with contact to beach sand and with fishing.

\section{Animals}

There was no association between illness and contact to animals or having a pet in general; however, cases were more likely to have had contact with animal feces (Table 3 ). Further, there was also an association between illness and 
having a pet dog and in particular a dog who had diarrhea in the 5-day exposure period. Lastly, cases were more likely to have had contact with cattle.

Table I Frequency and percentage of study cases and controls by demographic characteristics (excluding persons reporting foreign travel), Denmark 2016

\begin{tabular}{|c|c|c|}
\hline Characteristic & $\begin{array}{l}\text { Cases, } n(\%) \\
n=556\end{array}$ & $\begin{array}{l}\text { Controls, } n \text { (\%) } \\
\mathrm{N}=2,117\end{array}$ \\
\hline \multicolumn{3}{|l|}{ Age (years) } \\
\hline $\mathrm{I}-4$ & $106(19)$ & $254(12)$ \\
\hline $5-9$ & $53(10)$ & $339(16)$ \\
\hline $10-14$ & $50(9)$ & $350(17)$ \\
\hline $15-19$ & $101(18)$ & $359(18)$ \\
\hline $20-24$ & $\mathrm{II} 8(2 \mathrm{I})$ & $395(19)$ \\
\hline $25-30$ & $128(23)$ & $420(20)$ \\
\hline \multicolumn{3}{|l|}{ Gender } \\
\hline Male & $284(52)$ & $\mathrm{I}, 080(5 \mathrm{I})$ \\
\hline Female & $272(48)$ & $\mathrm{I}, 037(49)$ \\
\hline \multicolumn{3}{|l|}{ Region of residence } \\
\hline Capital & $189(34)$ & $74 I(35)$ \\
\hline Zealand & $78(14)$ & $318(15)$ \\
\hline South & $106(19)$ & $402(19)$ \\
\hline Mid & $122(22)$ & $423(20)$ \\
\hline North & $6 \mathrm{I}(\mathrm{II})$ & $233(\mathrm{II})$ \\
\hline \multicolumn{3}{|l|}{ Residential area } \\
\hline Rural & $70(13)$ & $275(13)$ \\
\hline Urban & $409(74)$ & $\mathrm{I}, 589(75)$ \\
\hline Unknown & $77(13)$ & $253(12)$ \\
\hline \multicolumn{3}{|l|}{ Occupation $^{\mathrm{a}}$} \\
\hline Full-time work/studies & $186(93)$ & $\mathrm{I}, 05 \mathrm{I}(92)$ \\
\hline Unemployed & $15(7)$ & $92(8)$ \\
\hline
\end{tabular}

Note: ${ }^{a}$ Over 18 years only (cases $n=267$, controls $=887$ ).

\section{Eating habits and kitchen hygiene}

Eating in a café/restaurant or fast food restaurant carried an increased risk of infection as did eating food served outdoors and own food consumed during a picnic in the countryside or forest (Table 3). Eating meat cooked on barbecue (at home) was also associated with infection.

Considering hygiene practices at home, handling of fresh chicken in the 5-day exposure period was associated with an increased risk of infection.

\section{Food and drink}

There was no association between illness and consumption of pork, duck, goose, game, or any deli meat as a habit or during the 5-day exposure period. Cases were more likely to consume chicken in general and to have consumed whole chicken, chicken fillet, or chicken thighs in the exposure period. The analyses further identified an increased risk of illness associated with consumption of beef mince and steaks (Table 3).

Consumption of specific vegetables was not associated with illness. However, fresh strawberries, raspberries, and blueberries increased the risk of infection as did consumption of smoothies prepared with frozen berries.

Lastly, cases were more likely than controls to have consumed unpasteurized milk and to live in a household with drinking water supplied from a private water supply.

\section{Other exposures}

Participants were asked about their own and family members' medical history and use of medication. Among these, the use

Table 2 Determinants for Campylobacter infection associated with foreign travel, Denmark 2016

\begin{tabular}{|c|c|c|c|c|}
\hline Exposure & $\begin{array}{l}\text { Cases }(\mathrm{N}=302) \\
\mathrm{n}(\%)\end{array}$ & $\begin{array}{l}\text { Controls (N=248) } \\
\text { n (\%) }\end{array}$ & $\mathbf{O R}^{\mathbf{a}}$ & $95 \% \mathrm{Cl}$ \\
\hline \multicolumn{5}{|l|}{ Destination } \\
\hline Turkey & $27(8.9)$ & $9(3.6)$ & 3.6 & $1.4-9.3$ \\
\hline Thailand & $13(4.3)$ & $\mathrm{I}(0.4)$ & 9.9 & $1.2-78.8$ \\
\hline Indonesia & $22(7.3)$ & $\mathrm{I}(0.4)$ & 12.2 & $1.6-92.8$ \\
\hline Asia (others) & $45(14.9)$ & $9(3.6)$ & 3.0 & I.4-6.7 \\
\hline Africa & $35(11.6)$ & $3(1.2)$ & 6.9 & $2.1-23.1$ \\
\hline Northern Europe ${ }^{b}$ & $18(6.0)$ & $71(28.6)$ & 0.2 & $0.1-0.3$ \\
\hline Scandinavia $^{c}$ & $9(3.0)$ & $39(15.7)$ & 0.1 & $0.06-0.3$ \\
\hline \multicolumn{5}{|l|}{ Accommodation } \\
\hline Bed \& breakfast & $27(8.9)$ & II (4.4) & 2.5 & $1.7-5.3$ \\
\hline \multicolumn{5}{|l|}{ Meals } \\
\hline Street kitchens & $67(22.2)$ & $16(6.5)$ & 2.7 & $1.4-5.0$ \\
\hline Cooked own food & $99(32.8)$ & $124(50.0)$ & 0.5 & $0.3-0.7$ \\
\hline \multicolumn{5}{|l|}{ Environment } \\
\hline Contact to sand, soil, or mud & $239(79.1)$ & $178(7 \mid .8)$ & 1.8 & $1.1-2.8$ \\
\hline Swimming in sea water & $187(6 \mid .9)$ & $116(46.9)$ & 1.7 & $1.1-2.8$ \\
\hline
\end{tabular}

Notes: ${ }^{\mathrm{O} O R s}$ are adjusted for the confounding effect of age, sex, and season. ${ }^{\mathrm{b}}$ Germany, UK, Holland, Austria, and Belgium. cFinland, Norway, Sweden, and Iceland. 
Table 3 Univariate determinants for Campylobacter infection, Denmark 2016

\begin{tabular}{|c|c|c|c|c|}
\hline Exposure & $\begin{array}{l}\text { Cases exposed } \\
\text { n (\%) }\end{array}$ & $\begin{array}{l}\text { Controls exposed } \\
\text { n (\%) }\end{array}$ & $\begin{array}{l}\text { Adjusted OR } \\
(95 \% \mathrm{CI})\end{array}$ & $P$-value \\
\hline \multicolumn{5}{|l|}{ Demography } \\
\hline Lives in an urban area* & $409(85)$ & $\mathrm{I}, 572(86)$ & $0.8(0.6,1.2)$ & 0.32 \\
\hline Visited weekend cottage & $28(6)$ & $116(6)$ & $0.9(0.6,1.4)$ & 0.67 \\
\hline \multicolumn{5}{|l|}{ Recreational activities and environmental factors } \\
\hline Went for a walk & $443(85)$ & I,79I (88) & $0.9(0.6,1.2)$ & 0.37 \\
\hline Gardening work & $248(48)$ & I, II 8 (55) & $1.0(0.8,1.4)$ & 0.72 \\
\hline Running on asphalt & $298(58)$ & $\mathrm{I}, 478(72)$ & $0.7(0.6,0.9)$ & $<0.01$ \\
\hline Running on soil & $266(52)$ & $\mathrm{I}, 30 \mathrm{I}(64)$ & $0.7(0.6,0.9)$ & $<0.05$ \\
\hline Riding a bicycle on asphalt & $311(60)$ & $\mathrm{I}, 366(67)$ & $0.8(0.7,1.0)$ & 0.10 \\
\hline Riding a bicycle on soil & $210(4 I)$ & $847(42)$ & $1.0(0.8,1.2)$ & 0.99 \\
\hline Outdoor sports & $15 \mid(29)$ & $713(35)$ & $1.2(1.0,1.6)$ & 0.10 \\
\hline Stayed outdoors in rain & $28(6)$ & $116(6)$ & $0.9(0.6,1.2)$ & 0.31 \\
\hline Bathed in an indoor swimming pool & $48(9)$ & $333(16)$ & $0.7(0.5,1.1)$ & 0.09 \\
\hline Bathed in sea water & $43(8)$ & $94(5)$ & $1.6(1.0,2.4)$ & $<0.05$ \\
\hline Bathed in fresh water & $33(6)$ & $24(I)$ & $6.0(3.0,11.9)$ & $<0.001$ \\
\hline Bathed in a paddling pool & $54(10)$ & $79(4)$ & $3.0(1.9,4.6)$ & $<0.001$ \\
\hline Contact to beach sand & $150(29)$ & $290(14)$ & $2.3(1.8,3.0)$ & $<0.001$ \\
\hline Sailing & $19(4)$ & $59(3)$ & $1.2(0.6,2.1)$ & 0.62 \\
\hline Fishing & $22(4)$ & $43(2)$ & $2.0(1.1,3.7)$ & $<0.05$ \\
\hline \multicolumn{5}{|l|}{ Eating } \\
\hline Café or restaurant & $256(50)$ & $758(37)$ & $1.5(1.2,1.8)$ & $<0.01$ \\
\hline Fast food restaurant & $314(6 \mid)$ & $\mathrm{I}, 030(5 \mathrm{I})$ & I.4 (I.2, I.8) & $<0.01$ \\
\hline Canteen & $223(43)$ & $806(40)$ & I.I $(0.9$, I.3) & 0.56 \\
\hline Outdoor serving & $|2|(24)$ & $248(12)$ & I.8 $(1.4,2.3)$ & $<0.001$ \\
\hline Packed lunch eaten outside & $129(25)$ & $515(25)$ & $1.0(0.7,1.2)$ & 0.75 \\
\hline Eating in own garden & $146(28)$ & $517(25)$ & $0.9(0.7,1.2)$ & 0.43 \\
\hline Picnic in a forest/countryside (own food) & $60(8)$ & $153(2)$ & I.8 $(1.2,2.6)$ & $<0.01$ \\
\hline \multicolumn{5}{|l|}{ Meat } \\
\hline Vegetarian* & $4(1)$ & $27(I)$ & $0.4(0.1,1.3)$ & 0.13 \\
\hline Eat poultry* & $512(99)$ & $1,986(97)$ & $3.5(1.2,10.1)$ & $<0.05$ \\
\hline Eat pork* & $479(93)$ & $1,915(94)$ & $0.8(0.5,1.2)$ & 0.25 \\
\hline Eat beef* & $494(97)$ & I,97। (98) & $1.0(0.5,1.9)$ & 0.98 \\
\hline Whole chicken & $163(24)$ & $372(12)$ & $2.2(1.8,2.9)$ & $<0.001$ \\
\hline Boneless chicken fillets & $386(75)$ & $\mathrm{I}, \mathrm{I} 83(58)$ & $2.1(1.6,2.6)$ & $<0.001$ \\
\hline Chicken thighs & $169(33)$ & $501(25)$ & $1.6(1.2,2.0)$ & $<0.001$ \\
\hline Minced chicken & $88(17)$ & $254(13)$ & $1.3(1.0,1.8)$ & 0.06 \\
\hline Turkey & $28(5)$ & $|5|(7)$ & $0.6(0.4,1.0)$ & $<0.05$ \\
\hline Duck or goose & $25(5)$ & $134(7)$ & $0.7(0.4,1.0)$ & 0.07 \\
\hline Chicken bought fresh, prepared home & $445(86)$ & $\mathrm{I}, 734 /(85)$ & $1.2(0.9,1.6)$ & 0.28 \\
\hline Chicken bought frozen, prepared home & 200 (39) & $761(38)$ & $1.0(0.8,1.3)$ & 0.79 \\
\hline Chicken liver & $8(2)$ & $48(2)$ & $0.6(0.3,1.4)$ & 0.27 \\
\hline Pork chops & $253(53)$ & $908(48)$ & $1.2(0.9,1.5)$ & 0.07 \\
\hline Minced pork & $269(56)$ & $\mathrm{I}, 004(53)$ & I.I $(0.9,1.4)$ & 0.27 \\
\hline Pork sausages & $262(55)$ & $1,078(57)$ & $1.0(0.8,1.2)$ & 0.76 \\
\hline Beef (steak) & $249(5 I)$ & $803(4 I)$ & I.3 (I.I, I.7) & $<0.01$ \\
\hline Minced beef & $449(91)$ & $1,618(82)$ & $2.5(1.8,3.6)$ & $<0.001$ \\
\hline \multicolumn{5}{|l|}{ Vegetables and fruit } \\
\hline Lettuce & $352(69)$ & $1,299(64)$ & I.I $(0.9,1.4)$ & 0.40 \\
\hline Raw carrots & $339(67)$ & $1,462(72)$ & $0.9(0.7,1.1)$ & 0.31 \\
\hline Raw fresh peas & $144(28)$ & $445(22)$ & $1.2(1.0,1.6)$ & 0.09 \\
\hline Unpeeled apples & $357(70)$ & $1,519(72)$ & $1.0(0.7,1.2)$ & 0.70 \\
\hline Grapes & $284(56)$ & $\mathrm{I}, 048(5 \mathrm{I})$ & $1.2(1.0,1.5)$ & 0.10 \\
\hline Strawberries (fresh) & $184(36)$ & $505(25)$ & $1.6(1.3,2.1)$ & $<0.001$ \\
\hline Raspberries (fresh) & $106(2 I)$ & $28 I(14)$ & $1.5(1.1,1.9)$ & $<0.01$ \\
\hline Blueberries (fresh) & $129(25)$ & $370(18)$ & I.4 (I.I, I.8) & $<0.01$ \\
\hline Smoothie prepared with frozen berries & $95(19)$ & $306(15)$ & $1.3(1.0,1.8)$ & $<0.05$ \\
\hline
\end{tabular}

(Continued) 
Table 3 (Continued)

\begin{tabular}{|c|c|c|c|c|}
\hline Exposure & $\begin{array}{l}\text { Cases exposed } \\
\text { n (\%) }\end{array}$ & $\begin{array}{l}\text { Controls exposed } \\
\text { n (\%) }\end{array}$ & $\begin{array}{l}\text { Adjusted OR } \\
(95 \% \mathrm{Cl})\end{array}$ & $P$-value \\
\hline \multicolumn{5}{|l|}{ Food handling and preparation } \\
\hline Handled raw chicken & I6I (59) & $336(35)$ & $2.1(1.6,2.9)$ & $<0.001$ \\
\hline Handles raw chicken* & $274(55)$ & 951 (48) & $0.8(0.6,1.1)$ & 0.20 \\
\hline $\begin{array}{l}\text { Washes hands before and after handling } \\
\text { chicken* }\end{array}$ & $245(90)$ & $847(89)$ & $1.4(0.9,2.3)$ & 0.13 \\
\hline Does not wash hands when handling chicken* & $2(I)$ & $4(0.5)$ & I.4 $(0.2,8.9)$ & 0.71 \\
\hline Cleans handling surface with a cloth* & $13(5)$ & $82(9)$ & $0.5(0.2,0.9)$ & $<0.05$ \\
\hline Cleans handling surface with water and soap* & $235(86)$ & $793(83)$ & $1.3(0.8,2.0)$ & 0.24 \\
\hline Does not clean handling surface* & $6(2)$ & $25(3)$ & $0.8(0.3,2.1)$ & 0.62 \\
\hline Prepares chicken pink or rare* & $15(3)$ & $34(2)$ & $1.3(0.7,2.6)$ & 0.40 \\
\hline Meat prepared on a barbecue & $182(36)$ & $512(25)$ & I.4 (I.I, I.8) & $<0.01$ \\
\hline Meat prepared in a microwave & $173(34)$ & $6 I 1(30)$ & I.I $(0.8,1.3)$ & 0.59 \\
\hline \multicolumn{5}{|l|}{ Drink } \\
\hline Unpasteurized milk & $27(5)$ & $52(3)$ & $1.9(1.1,3.1)$ & $<0.05$ \\
\hline Tap water & $485(95)$ & $1,979(93)$ & $0.4(0.2,0.7)$ & $<0.01$ \\
\hline Water from a spring or stream & $15(3)$ & $22(1)$ & $2.7(1.2,5.8)$ & $<0.05$ \\
\hline Household drinking water from private well & $27(6)$ & $39(2)$ & $2.9(1.6,5.2)$ & $<0.001$ \\
\hline \multicolumn{5}{|l|}{ Animals } \\
\hline Contact to animals & $360(73)$ & $\mathrm{I}, 548(78)$ & $0.7(0.6,0.9)$ & 0.2 \\
\hline Dogs & $290(59)$ & $1,186(60)$ & $1.0(0.8,1.2)$ & 0.67 \\
\hline Cats & $180(36)$ & $797(40)$ & $0.8(0.7,1.1)$ & 0.14 \\
\hline Birds/poultry & $7(1)$ & $73(4)$ & $1.0(0.7,1.5)$ & 0.94 \\
\hline Pigs & $16(3)$ & $36(2)$ & $1.7(0.9,3.4)$ & 0.1 \\
\hline Cattle & $53(\mathrm{II})$ & $82(4)$ & $2.4(1.6,3.6)$ & $<0.001$ \\
\hline Contact to animal feces & III (3I) & $96(6)$ & $6.8(4.7,9.7)$ & $<0.001$ \\
\hline Owns a pet* & $233(42)$ & $1,019(48)$ & I.I $(0.8,1.3)$ & 0.64 \\
\hline Dog* & $175(31)$ & $594(28)$ & $1.5(I .1,2.1)$ & $<0.05$ \\
\hline Handles feces* & $70(13)$ & $279(13)$ & $1.0(0.6,1.7)$ & 0.89 \\
\hline Dog had diarrhea & $29(5)$ & $29(1)$ & $5.9(2.8,12.1)$ & $<0.001$ \\
\hline Cat* & $89(16)$ & $480(23)$ & $0.6(0.4,0.8)$ & $<0.01$ \\
\hline Handles feces/empties litter tray* & $10(2)$ & $80(4)$ & $0.5(0.2,1.2)$ & 0.12 \\
\hline Cat had diarrhea & $3(I)$ & $13(I)$ & $1.3(0.3,5.5)$ & 0.76 \\
\hline Birds/chickens* & $23(4)$ & $88(4)$ & $1.0(0.6,1.8)$ & 0.91 \\
\hline Handles feces/cleans chicken coop* & $4(1)$ & $29(I)$ & $0.3(0.1,1.0)$ & 0.06 \\
\hline Contact to eggs* & $19(3)$ & $73(3)$ & $2.2(0.5,9.6)$ & 0.30 \\
\hline \multicolumn{5}{|l|}{ Other exposures } \\
\hline Suffers from chronic disease* & $52(10)$ & $185(9)$ & $0.9(0.7,1.3)$ & 0.66 \\
\hline Use of antibiotics++ & $17(3)$ & $34(1)$ & $2.0(1.0,4.0)$ & $<0.05$ \\
\hline Use of proton pump inhibitors++ & $29(6)$ & $20(1)$ & $3.9(2.0,7.5)$ & $<0.001$ \\
\hline Travel abroad with overnight stay+ & $309(35)$ & $298(10)$ & $4.6(3.7,5.7)$ & $<0.001$ \\
\hline Household member with diarrhea & $40(8)$ & $110(6)$ & $1.6(1.0 ; 2.4$ & $<0.05$ \\
\hline \multicolumn{5}{|l|}{ Exposures relevant only for persons $>18^{*}$} \\
\hline Currently working & $128(48)$ & $319(36)$ & $1.8(1.3,2.4)$ & $<0.001$ \\
\hline Contact to hospital admitted patients & II (4) & $62(7)$ & $0.5(0.2,1.5)$ & 0.2 \\
\hline Contact to patients in non-hospital settings & $29(\mathrm{II})$ & $44(5)$ & $2.2(1.0,4.9)$ & $<0.05$ \\
\hline Contact to water or sewage & $8(3)$ & $27(3)$ & $1.3(0.4,4.9)$ & 0.7 \\
\hline \multicolumn{5}{|l|}{ Exposures relevant only for persons $<18^{*}$} \\
\hline Forest nursery/kindergarten & $81(28)$ & $27 \mid(22)$ & I.2 $(0.6,0.9)$ & 0.2 \\
\hline Animals in the nursery/kindergarten & $|2|(42)$ & $394(32)$ & $1.3(1.0,1.8)$ & $<0.05$ \\
\hline Uses a dummy & $110(38)$ & $394(32)$ & $1.0(0.1,1.7)$ & 0.9 \\
\hline Uses a snuggle toy & $46(16)$ & $234(19)$ & $1.0(0.5,1.7)$ & 0.9 \\
\hline Animals at school/college & $32(11)$ & $86(7)$ & $1.6(0.7,3.3)$ & 0.1 \\
\hline After school job & $72(25)$ & $221(18)$ & $1.2(0.7,2.0)$ & 0.5 \\
\hline Babysitting & $17(6)$ & $49(4)$ & $2.5(0.4,16.1)$ & 0.3 \\
\hline Contact to animals & $46(16)$ & $98(8)$ & $2.7(1.1,3.0)$ & $<0.01$ \\
\hline Contact to food & $38(13)$ & $160(13)$ & $0.9(0.3,3.3)$ & 0.9 \\
\hline
\end{tabular}

Notes: aRs are adjusted for the confounding effect of gender, age, residential area (urban or rural), and season. Exposures refer to a 5-day exposure period prior to onset of symptoms (cases) or completion of questionnaire (controls) apart from (*) habits or baseline, (+) 14-day exposure period, and (++) I-month exposure period. 
of antibiotics and proton pump inhibitors (PPIs) in the last month/month prior to developing symptoms and a household member suffering from diarrhea in the 5-day exposure period were associated with illness.

\section{Specific exposures for adults and children}

To account for age-specific exposures, adults (over 18 years of age) and children were asked different questions relating to occupation or schooling. Analyses showed that adults who worked - and in particular work involving patient contact in non-hospital settings (eg, home care) - were at higher risk of infection. Children who had an after school job with contact to animals (eg, dog walking) also had a higher risk of campylobacteriosis.

\section{Protective factors}

A number of factors were independently associated with a reduced risk of infection, including running (on both soil and asphalt) and having a pet cat (Table 3 ). With respect to food and drink, consumption of turkey and tap water (at home) also carried a lower risk of infection.

\section{Multivariate analysis of risk factors}

\section{All study participants, ages $\mathrm{I}-30$ years}

A range of both food- and non-food-related exposures were associated with illness after adjusting for the effect of other variables (Table 4). The explorative analyses identified an interaction between minced beef and barbecued meat which was included in this model. Consumption of chicken fillets, whole chicken, beef mince, and meat prepared on a barbecue were all associated with an increased risk of illness.
Of environmental factors, bathing in fresh water, contact to beach sand, and having household drinking water from a private well carried increased risk of disease in the final model. In addition, the model showed that contact to animal feces, owning a pet dog with diarrhea, and the use of PPIs were associated with illness.

These independent determinants predicted almost half of the variation in illness $\left(R^{2}=0.48\right)$.

The calculated PAFs showed that avoiding consumption of chicken and minced beef, and contact to animals and pet dogs with diarrhea would result in the highest reduction in the number of infections (Table 4). The remaining variables accounted for a smaller proportion of the number of campylobacteriosis cases.

\section{Small children, ages $\mathrm{I}-5$ years}

The separate model constructed for small children indicated that both food and non-food exposures were important and independently associated with campylobacteriosis (Table 4). Contact to animal feces and bathing in a paddling pool were the two sole environmental factors included. Having a pet dog was also associated with illness. With respect to food, the model included consumption of minced beef, whole chicken, and fresh strawberries.

These independent determinants predicted slightly more than half of the variation in illness $\left(R^{2}=0.51\right)$.

For children, not consuming chicken and minced beef and not having contact with animal feces and dogs would also result in a notable reduction in the number of infections (Table 4). Further, consumption of strawberries alone accounted for a relative $16 \%$ of cases.

Table 4 Multivariable risk factors for Campylobacter infection, Denmark 2016

\begin{tabular}{|c|c|c|c|c|c|}
\hline \multicolumn{3}{|l|}{$\begin{array}{l}\text { All persons } \\
\text { ( } N=556 \text { cases, } 2,117 \text { controls) }\end{array}$} & \multicolumn{3}{|l|}{$\begin{array}{l}\text { Children I-5 years } \\
(\mathrm{N}=\mid 25 \text { cases, } 32 \mid \text { controls) }\end{array}$} \\
\hline Exposure & $\mathrm{OR}^{\mathrm{a}}(95 \% \mathrm{CI})$ & $\begin{array}{l}\text { PAF } \\
\text { (\%) }\end{array}$ & Exposure & $\begin{array}{l}\text { OR }^{\mathrm{b}} \\
(95 \% \mathrm{Cl})\end{array}$ & PAF (\%) \\
\hline Use of proton pump inhibitors & $10.1(1.9-54.0)$ & 3 & Contact to animal feces & $62.4(8.2-472.6)$ & 8 \\
\hline Bathing in fresh water & $5.1(1.4-17.9)$ & 4 & Bathing in paddling pool & $13.6(1.9-97.0)$ & 8 \\
\hline Pet dog had diarrhea & $4.6(2.0-10.7)$ & 8 & Consumption of whole chicken & $12.3(2.8-53.0)$ & 14 \\
\hline Contact to animal feces & $4.3(2.1-8.6)$ & 12 & Consumption of minced beef & $11.2(1.2-104.1)$ & 33 \\
\hline Household water from private well & $2.7(1.0-7.6)$ & 2 & Consumption of fresh strawberries & $5.3(1.3-20.5)$ & 16 \\
\hline Consumption of minced beef & $2.6(1.1-6.3)$ & 29 & Having a pet dog & $3.8(1.1-13.1)$ & 21 \\
\hline Consumption of chicken fillets & $2.5(1.4-4.5)$ & 23 & & & \\
\hline Consumption of whole chicken & $2.1(1.2-3.7)$ & 6 & & & \\
\hline Contact to beach sand & $1.8(1.0-3.4)$ & 7 & & & \\
\hline Consumption of barbecued meat & $1.6(1.1-3.4)$ & 7 & & & \\
\hline
\end{tabular}

Notes: a ORs are adjusted for the confounding effect of gender, age, residential area (urban or rural), and season. ${ }^{\mathrm{b}}$ ORs are adjusted for the confounding effect of gender, residential area (urban or rural), and season.

Abbreviation: PAF, population attributable fraction. 


\section{Discussion}

In this national case-control study of campylobacteriosis determinants, we found that exposures related to the environment, animal contact, and food were associated with an increased risk of illness. The study is the largest ever undertaken in Denmark. Because it focuses on the younger age groups, the results are less influenced by bias from persons with partial immunity. The investigation generated response rates at high levels $(65 \%$ for cases and $66 \%$ for controls) for a non-telephone-based survey, highlighting the usefulness of online questionnaires but also the validity of the results. ${ }^{32}$ Lastly, we asked persons who reported traveling to provide specific information regarding exposures during their trip, rather than immediately excluding them from the study.

One of the primary aims of this study was to identify environmental risk factors for campylobacteriosis. The results show that contact to water in the environment was particularly important. There is a well-established link between Campylobacter infection and recreational water contact, ${ }^{22,25,33}$ especially in outbreak situations. ${ }^{12,34}$ Both fresh and sea water harbor Campylobacter spp. ${ }^{35,36}$ and our study suggests that $4 \%$ of sporadic Danish campylobacteriosis cases may be caused by recreational water contact - even double that for children using a paddling pool. Ingestion of water from a private (rather than public) household well also increased the risk of infection. Drinking water was implicated in several Campylobacter outbreaks $\mathrm{s}^{37,38}$ and associated with disease in case-control studies from other countries..$^{21,23,39}$ However, as the public water supply in Denmark, unlike most other European countries, is drawn almost exclusively from ground water rather than surface water, ${ }^{40}$ it is not unexpected that our study associates disease with drinking water from a private well. The final environmental determinant identified in this study was beach sand. Although not previously identified in any case-control study, it is not surprising as Campylobacter spp. are present in beach sand ${ }^{41}$ and indeed several Campylobacter outbreaks have been linked to incidental ingestion of mud. ${ }^{13,14}$

Another known risk factor for Campylobacter infection is interaction with animals. We found that contact to animal feces was a particular determinant for infection, accounting for as much as $12 \%$ of cases. Further, we confirm that contact to dogs, especially if the dog has diarrhea, also increases the risk of infection. For small children, having a pet dog was the second most important determinant identified in the study. On the contrary, having a pet cat was associated with a reduced risk of infection, possibly indicating the distinction "cat people" vs "dog people" (although this was not confirmed by interactions between the variables). These results confirm previous findings that contact to dogs and their feces carries an increased risk of campylobacteriosis for humans. ${ }^{20,23} \mathrm{In}$ general, the importance of proper hygiene measures during and after contact to dogs and their feces, especially for children, needs to be emphasized in public health settings.

For food-related exposures, consumption of chicken (whole chicken and chicken fillets) was associated with domestic Campylobacter infection. Our study showed that almost one third of Campylobacter cases in Denmark each year may be attributed to chicken. Although chicken liver, in the form of liver paté, has been identified as the source of several outbreaks as well as a risk factor for sporadic disease in other countries, ${ }^{42}$ it was not a determinant for infection in our study. Rather than eliminating chicken livers as a potential risk factor, we attribute this result to the low risk of exposure among our study population - which most likely reflects the age group studied (the frequency of chicken liver consumption increases with age). ${ }^{42}$ As an unexpected outcome, the results show that consumption of minced beef may be associated with campylobacteriosis. Campylobacter spp. have been isolated from cattle in both Denmark and other European countries, ${ }^{43-47}$ but the prevalence in beef is reported as minor. ${ }^{48-51}$ Minced beef/hamburger meat was identified as a risk factor in other case-control studies ${ }^{52,53}$ and even as a source of outbreaks, ${ }^{54-56}$ but it is not considered an important transmission route for Campylobacter in Denmark. The risk associated with minced beef may be a recent occurrence due to the introduction of Modified Atmosphere Packaging (MAP). Minced meat in a MAP has lower concentrations of $\mathrm{O}_{2}$, improving the shelf life and reducing discoloration, but during preparation the meat rapidly turns brown, increasing the risk of consumption before properly cooked. The separate model for small children indicated fresh strawberries as a source of infection. This is also an unexpected result given previous findings that fresh berries reduce the risk of infection. ${ }^{52,57}$ The risk from strawberries may be linked to hygiene practices (not washing the berries) as Danish children frequently eat strawberries either from the field when picking them or directly from the box if bought in retail. Our results point to minced beef and fresh strawberries as two new possible sources of infection to be investigated, and both of these are presently being examined by the Danish Food and Veterinary Administration as part of the national action plan against Campylobacter.

The questionnaire also examined medical history and use of medication, and our results confirm previous findings that the use of PPIs increases the risk of Campylobacter 
infection. ${ }^{58,59}$ Use of over-the-counter PPIs has increased during recent years, and this may be one of the driving factors behind the observed increase in Campylobacter in many countries. ${ }^{28,60}$ Interestingly, our study found an age-independent risk for the use of PPIs with very young children also reporting use of this medication. PPIs are not contraindicated for the use in children, and are prescribed for treatment of complicated reflux. ${ }^{61}$ For this age group in particular, our results highlight a potential public health concern correlated with the use of PPIs.

As a new addition to case-control studies of sporadic campylobacteriosis, we included an expanded analysis of travel-related cases. Our results confirm that infection abroad primarily occurs in Indonesia, Thailand, Africa, and Turkey. Cases in general could be classified as "adventurous" travelers, visiting more countries, and in particular countries outside Europe. Here, eating in street kitchens and staying in a Bed \& Breakfast carried the highest risk of infection, but also contact to water, sand soil, or mud were determinants of infection. On the other hand, persons who traveled to Scandinavia or Northern Europe and who cooked their own food had lower risk of infection. These countries are not "protective" in themselves as campylobacteriosis rates are also high in Northern Europe, but the low infection risk is most likely an indicator for better hygiene and consumption of safer foods when traveling closer to home. Several studies report that travelers in more exotic locations, frequently Asia, often do not follow the rules of eating and drinking safely. ${ }^{62-64}$

Campylobacteriosis is a disease of many unanswered questions, in particular with respect to determination of risk factors and their relative importance. For instance, persistently high incidences of Campylobacter in many countries despite intense poultry control efforts has been an argument for chicken not being the primary source of human infections. ${ }^{65,66}$ Overall, our results confirm that chicken meat is an important risk factor for campylobacteriosis. However, they also cast new light on the ongoing question of whether infections arise from more complex transmission routes ${ }^{66}$ - such as those from other food sources and the environment. The results presented here suggest that campylobacteriosis is not attributable to one primary food source but rather a combination of non-food and food factors. The relative importance of these factors is likely to vary between persons, locations, and even throughout the year.

The study size, age-specific inclusion criteria, and high response rates are all important strengths when interpreting our findings. Additionally, the independent determinants identified in the analyses all confirm previous knowledge about Campylobacter - albeit in more detail. Nevertheless, it is necessary to consider the potential biases commonly affecting case-control studies. Firstly, participation rates among cases and controls were high, resulting in an even distribution of exposures between the two groups. Secondly, using an online questionnaire eliminated interviewer bias. The third issue to consider is imperfect recall. Cases probably received their invitation 14-20 days after symptom onset and may have forgotten exposures in the period before symptom onset. However, all questions relating to the 5-day exposure period were also asked as "habit" questions (ie, "how often do you..."). Including these questions helps generate an overall image of each participant. For instance, a case who reports generally eating chicken up to five times per week is also likely to have eaten it in the 5 days before symptom onset. We therefore argue that the impact of recollection bias is negligible. In this study, we chose to exclude controls who reported suffering from symptoms of a gastrointestinal illness in the month prior to completing the questionnaire. Although often a standard practice in case-control studies, it has been suggested that such exclusions create bias as the control group has been amended to not exactly represent the population which gave rise to the cases. ${ }^{67}$ This may have resulted in the identification of artificial associations - particularly if the unknown gastrointestinal illness was associated with some of the determinants identified in this study. However, considering that only $5 \%$ of controls were excluded for this reason, this bias is unlikely to have had an impact on the results. Another source of bias was only including persons aged 1-30 years and effectively omitting around $60 \%$ of all notified campylobacteriosis cases from the study. This improves the estimates for the identified determinants but may also have caused bias by missing specific determinants in the older population. The potential effect of bias is also visible in the wide confidence intervals calculated for some risk factors in the multivariate models, particularly for small children. This indicates a higher degree of uncertainty associated with the results and most likely reflects the smaller sample size for some exposures. Another limitation of the study is not distinguishing between different Campylobacter spp. which may have overlooked species-specific risk factors. However, as $95 \%$ of all reported infections in Denmark are Campylobacter jejuni, ${ }^{68}$ variation between species is unlikely to have impacted the results. Indeed, omitting known Campylobacter coli infections from the analyses did not alter the outcomes (results not shown). Seasonality had the potential for causing bias in the results presented. Both Campylobacter infection rates ${ }^{1}$ and recreational/environmental exposures are highly seasonal. We aimed to minimize this bias by frequency-matching, ensur- 
ing that the number of controls included in any given month proportionally reflected the number of reported cases and that the relevant exposures were given appropriate weight in relation to the season. Finally, interpreting the results for risks of traveling need to be interpreted with the caution that all exposures whilst traveling were assumed to be equal, irrespective of destination - something which is most likely not the case.

\section{Conclusion}

Overall, the results from this study underpin that Campylobacter infection remains primarily a foodborne infection albeit with an important environmental component. The role of environmental factors in relation to Campylobacter infection is poorly understood and the Population Attributable Fractions calculated in this study indicate that environmental factors - primarily recreational water contact and contact to sand - could account for a large proportion of campylobacteriosis cases in this young population.

With respect to food, our findings confirm published evidence that chicken remains an important risk factor for campylobacteriosis. However, they also suggest minced beef as a potentially new source of infection. In order to confirm or reject this result, minced beef needs to be closely investigated for Campylobacter contamination at several levels of the food chain.

Combined, our results contribute significantly to a better understanding of the marked peak in cases during summer and of the "unexplained" cases of Campylobacter infection which are not related to chicken. Our results will be used to guide not only further research and control efforts but also to improve national guidelines for prevention of infection.

\section{Ethical considerations}

The Danish Data Protection Agency approved the study (journal 2012-54-0029). According to Danish regulations, ethical committee approval is not required for this study, as it did not involve analysis of biological material from human subjects.

\section{Acknowledgments}

We are very grateful to all subjects and parents who kindly participated in the study and to the Interview Center at Statens Serum Institut for initial screening of patients. We would also like to thank Gudrun Sandø, Mette Rørbæk Gantzhorn, Hanne Rosenquist, and Louise Boysen for providing constructive comments on the questionnaire and the study design. This project was supported by the Danish Food and Veterinary Administration, under the Ministry of Environment and Food of Denmark.

\section{Disclosure}

The authors report no conflicts of interest in this work.

\section{References}

1. Kuhn KG, Nielsen EM, Mølbak K, Ethelberg S. Epidemiology of campylobacteriosis in Denmark 2000-2015. Zoonoses Public Health. 2018;65(1):59-66.

2. European Food Safety Authority, European Centre for Disease Prevention and Control. The European Union summary report on trends and sources of zoonoses, zoonotic agents and food-borne outbreaks in 2015. Efsa J. 2016;14(12).

3. Marder EP, Cieslak PR, Cronquist AB, et al. Incidence and Trends of Infections with Pathogens Transmitted Commonly Through Food and the Effect of Increasing Use of Culture-Independent Diagnostic Tests on Surveillance - Foodborne Diseases Active Surveillance Network, 10 U.S. Sites, 2013-2016. MMWR Morb Mortal Wkly Rep. 2017;66(15): 397-403.

4. Moffatt CRM, Glass K, Stafford R, D'Este C, Kirk MD. The campylobacteriosis conundrum - examining the incidence of infection with Campylobacter sp. in Australia, 1998-2013. Epidemiol Infect. 2017;145(04):839-847.

5. Hald B, Skov MN, Nielsen EM, et al. Campylobacter jejuni and Campylobacter coli in wild birds on Danish livestock farms. Acta Vet Scand. 2016;58:11.

6. Campagnolo ER, Philipp LM, Long JM, Hanshaw NL. Pet-associated Campylobacteriosis: A persisting public health concern. Zoonoses Public Health. 2018;65(3):304-311.

7. Kaakoush NO, Castaño-Rodríguez N, Mitchell HM, Man SM. Global Epidemiology of Campylobacter Infection. Clin Microbiol Rev. 2015;28(3):687-720.

8. Havelaar AH, van Pelt W, Ang CW, et al. Immunity to Campylobacter: its role in risk assessment and epidemiology. Crit Rev Microbiol. 2009;35(1):1-22.

9. Multistate Outbreak of Multidrug-Resistant Campylobacter Infections Linked to Contact with Pet Store Puppies | September 2017 | Salmonella |CDC. Available from: https://www.cdc.gov/campylobacter/outbreaks/ puppies-9-17/index.html. Published December 14, 2017. Accessed January 29, 2018.

10. Kuhn KG, Falkenhorst G, Emborg HD, et al. Epidemiological and serological investigation of a waterborne Campylobacter jejuni outbreak in a Danish town. Epidemiol Infect. 2017;145(4):701-709.

11. Lahti E, Rehn M, Ockborn G, et al. Outbreak of Campylobacteriosis Following a Dairy Farm Visit: Confirmation by Genotyping. Foodborne Pathog Dis. 2017;14(6):326-332.

12. Harder-Lauridsen NM, Kuhn KG, Erichsen AC, Mølbak K, Ethelberg S. Gastrointestinal illness among triathletes swimming in non-polluted versus polluted seawater affected by heavy rainfall, Denmark, 20102011. PLoS One. 2013;8(11):e78371.

13. Stuart TL, Sandhu J, Stirling R, et al. Campylobacteriosis outbreak associated with ingestion of mud during a mountain bike race. Epidemiol Infect. 2010;138(12):1695-1703.

14. Zeigler M, Claar C, Rice D, et al. Outbreak of campylobacteriosis associated with a long-distance obstacle adventure race--Nevada, October 2012. MMWR Morb Mortal Wkly Rep. 2014;63(17):375-378.

15. Joensen KG, Kuhn KG, Müller L, et al. Whole-genome sequencing of Campylobacter jejuni isolated from Danish routine human stool samples reveals surprising degree of clustering. Clin Microbiol Infect. 2018;24(2):201.e5-201.e8.

16. Neimann J, Engberg J, Mølbak K, Wegener HC. A case-control study of risk factors for sporadic campylobacter infections in Denmark. Epidemiol Infect. 2003;130(3):353-366.

17. Ethelberg S, Simonsen J, Gerner-Smidt P, Olsen KE, Mølbak K. Spatial distribution and registry-based case-control analysis of Campylobacter infections in Denmark, 1991-2001. Am J Epidemiol. 2005;162(10):1008-1015. 
18. Wingstrand A, Neimann J, Engberg J, et al. Fresh chicken as main risk factor for campylobacteriosis, Denmark. Emerg Infect Dis. 2006;12(2):280-284.

19. Carrique-Mas J, Andersson Y, Hjertqvist M, Svensson A, Torner A, Giesecke J. Risk factors for domestic sporadic campylobacteriosis among young children in Sweden. Scand J Infect Dis. 2005;37(2):101-110.

20. Stafford RJ, Schluter P, Kirk M, et al. A multi-centre prospective casecontrol study of campylobacter infection in persons aged 5 years and older in Australia. Epidemiol Infect. 2007;135(6):978-988.

21. Domingues AR, Pires SM, Halasa T, Hald T. Source attribution of human campylobacteriosis using a meta-analysis of case-control studies of sporadic infections. Epidemiol Infect. 2012;140(6):970-981.

22. Mughini Gras L, Smid JH, Wagenaar JA, et al. Risk factors for campylobacteriosis of chicken, ruminant, and environmental origin: a combined case-control and source attribution analysis. PLoS One. 2012;7(8):e42599.

23. Macdonald E, White R, Mexia R, et al. Risk Factors for Sporadic Domestically Acquired Campylobacter Infections in Norway 2010-2011: A National Prospective Case-Control Study. PLoS One. 2015;10(10):e0139636.

24. Bassal R, Ovadia A, Bromberg M, et al. Risk Factors for Sporadic Infection With Campylobacter Spp. Among Children in Israel: A Casecontrol Study. Pediatr Infect Dis J. 2016;35(3):249-252.

25. Ravel A, Pintar K, Nesbitt A, Pollari F. Non food-related risk factors of campylobacteriosis in Canada: a matched case-control study. BMC Public Health. 2016;16(1):1016.

26. Rosner BM, Schielke A, Didelot X, et al. A combined case-control and molecular source attribution study of human Campylobacter infections in Germany, 2011-2014. Sci Rep. 2017;7(1):5139.

27. Casey E, Fitzgerald E, Lucey B. Towards understanding clinical campylobacter infection and its transmission: time for a different approach? Br J Biomed Sci. 2017;74(2):53-64.

28. Strachan NJ, Rotariu O, Macrae M, et al. Operationalising factors that explain the emergence of infectious diseases: a case study of the human campylobacteriosis epidemic. PLoS One. 2013;8(11):e79331.

29. Ailes E, Scallan E, Berkelman RL, Kleinbaum DG, Tauxe RV, Moe CL. Do differences in risk factors, medical care seeking, or medical practices explain the geographic variation in campylobacteriosis in Foodborne Diseases Active Surveillance Network (FoodNet) sites? Clin Infect Dis. 2012;54(Suppl 5):S464-S471.

30. Havelaar AH, Swart A. Impact of waning acquired immunity and asymptomatic infections on case-control studies for enteric pathogens. Epidemics. 2016;17:56-63.

31. Voldstedlund M, Haarh M, Mølbak K. MiBa Board of Representatives. The Danish Microbiology Database (MiBa) 2010 to 2013. Euro Surveill Bull Eur Sur Mal Transm Eur Commun Dis Bull. 2014;19(1).

32. Morton LM, Cahill J, Hartge P. Reporting participation in epidemiologic studies: a survey of practice. Am J Epidemiol. 2006;163(3):197-203.

33. Schönberg-Norio D, Takkinen J, Hänninen ML, et al. Swimming and Campylobacter infections. Emerg Infect Dis. 2004;10(8):1474-1477.

34. Dale K, Kirk M, Sinclair M, Hall R, Leder K. Reported waterborne outbreaks of gastrointestinal disease in Australia are predominantly associated with recreational exposure. Aust N Z J Public Health. 2010;34(5): 527-530.

35. Kovanen S, Kivistö R, Llarena AK, et al. Tracing isolates from domestic human Campylobacter jejuni infections to chicken slaughter batches and swimming water using whole-genome multilocus sequence typing. Int J Food Microbiol. 2016;226:53-60.

36. Moore JE, Caldwell PS, Millar BC, Murphy PG. Occurrence of Campylobacter spp. in water in Northern Ireland: implications for public health. Ulster Med J. 2001;70(2):102-107.

37. Guzman-Herrador B, Carlander A, Ethelberg S, et al. Waterborne outbreaks in the Nordic countries, 1998 to 2012. Euro Surveill. 2015;20(24):21160.

38. Nichols G, Lane C, Asgari N, Verlander NQ, Charlett A. Rainfall and outbreaks of drinking water related disease and in England and Wales. J Water Health. 2009;7(1):1-8.
39. Friedman CR, Hoekstra RM, Samuel M, et al. Risk factors for sporadic Campylobacter infection in the United States: A case-control study in FoodNet sites. Clin Infect Dis. 2004;38(Suppl 3):S285-S296.

40. Voutchkova DD, Hansen B, Ernstsen V, Kristiansen SM. Nationwide Drinking Water Sampling Campaign for Exposure Assessments in Denmark. Int J Environ Res Public Health. 2018;15(3):467.

41. Bolton FJ, Surman SB, Martin K, Wareing DR, Humphrey TJ. Presence of Campylobacter and Salmonella in sand from bathing beaches. Epidemiol Infect. 1999;122(1):7-13.

42. Jones AK, Rigby D, Burton M, et al. Restaurant Cooking Trends and Increased Risk for Campylobacter Infection. Emerg Infect Dis. 2016;22(7):1208-1215.

43. Nielsen EM, Fussing V, Engberg J, Nielsen NL, Neimann J. Most Campylobacter subtypes from sporadic infections can be found in retail poultry products and food animals. Epidemiol Infect. 2006;134(4):758-767.

44. Thépault A, Poezevara T, Quesne S, Rose V, Chemaly M, Rivoal K. Prevalence of Thermophilic Campylobacter in Cattle Production at Slaughterhouse Level in France and Link Between $C$. jejuni Bovine Strains and Campylobacteriosis. Front Microbiol. 2018;9:471.

45. Kovac J, Stessl B, Čadež N, et al. Population structure and attribution of human clinical Campylobacter jejuni isolates from central Europe to livestock and environmental sources. Zoonoses Public Health. 2018;65(1):51-58.

46. Escher R, Brunner C, von Steiger N, et al. Clinical and epidemiological analysis of Campylobacter fetus subsp. fetus infections in humans and comparative genetic analysis with strains isolated from cattle. $B M C$ Infect Dis. 2016;16:198.

47. Grove-White DH, Leatherbarrow AJ, Cripps PJ, Diggle PJ, French NP. Molecular epidemiology and genetic diversity of Campylobacter jejuni in ruminants. Epidemiol Infect. 2011;139(11):1661-1671.

48. Nielsen EM, Engberg J, Madsen M. Distribution of serotypes of Campylobacter jejuni and C. coli from Danish patients, poultry, cattle and swine. FEMS Immunol Med Microbiol. 1997;19(1):47-56.

49. Hakkinen M, Heiska H, Hänninen ML. Prevalence of Campylobacter spp. in cattle in Finland and antimicrobial susceptibilities of bovine Campylobacter jejuni strains. Appl Environ Microbiol. 2007;73(10):3232-3238.

50. Lammerding AM, Garcia MM, Mann ED, et al. Prevalence of Salmonella and Thermophilic Campylobacter in Fresh Pork, Beef, Veal and Poultry in Canada. J Food Prot. 1988;51(1):47-52.

51. Zhao C, Ge B, de Villena J, et al. Prevalence of Campylobacter spp., Escherichia coli, and Salmonella serovars in retail chicken, turkey, pork, and beef from the Greater Washington, D.C., area. Appl Environ Microbiol. 2001;67(12):5431-5436.

52. Kapperud G, Skjerve E, Bean NH, Ostroff SM, Lassen J. Risk factors for sporadic Campylobacter infections: results of a case-control study in southeastern Norway. J Clin Microbiol. 1992;30(12):3117-3121.

53. Gallay A, Bousquet V, Siret V, et al. Risk factors for acquiring sporadic Campylobacter infection in France: results from a national case-control study. J Infect Dis. 2008;197(10):1477-1484.

54. Greig JD, Ravel A. Analysis of foodborne outbreak data reported internationally for source attribution. Int J Food Microbiol. 2009;130(2):77-87.

55. Marler Clark Network. Foodborne Illness Outbreak Database. Available from: http://www.outbreakdatabase.com/. Accessed October 16, 2018.

56. Public Health England. Campylobacter data 2006 to 2015. National laboratory data for residents of England and Wales. Available from: https://assets.publishing.service.gov.uk/government/uploads/system/ uploads/attachment_data/file/597752/Campylobacter_2016_Data.pdf. Accessed October 16, 2018

57. Whiley H, van den Akker B, Giglio S, Bentham R. The role of environmental reservoirs in human campylobacteriosis. Int J Environ Res Public Health. 2013;10(11):5886-5907.

58. Doorduyn Y, van den Brandhof WE, van Duynhoven YT, Breukink BJ, Wagenaar JA, van Pelt W. Risk factors for indigenous Campylobacter jejuni and Campylobacter coli infections in The Netherlands: a casecontrol study. Epidemiol Infect. 2010;138(10):1391-1404. 
59. Hafiz RA, Wong C, Paynter S, David M, Peeters G. The Risk of Community-Acquired Enteric Infection in Proton Pump Inhibitor Therapy: Systematic Review and Meta-analysis. Ann Pharmacother. 2018;52(7):613-622.

60. Bouwknegt M, van Pelt W, Kubbinga ME, Weda M, Havelaar AH. Potential association between the recent increase in campylobacteriosis incidence in the Netherlands and proton-pump inhibitor use - an ecological study. Euro Surveill. 2014;19(32):20873.

61. Bell JC, Schneuer FJ, Harrison C, et al. Acid suppressants for managing gastro-oesophageal reflux and gastro-oesophageal reflux disease in infants: a national survey. Arch Dis Child. 2018;103(7):660-664.

62. Kass B. Traveller's diarrhoea. Aust Fam Physician. 2005;34(4):243-247.

63. Bryant HE, Csokonay WM, Love M, Love EJ. Self-reported illness and risk behaviours amongst Canadian travellers while abroad. Can J Public Health. 1991;82(5):316-319.
64. Migault C, Kanagaratnam L, Nguyen Y. Poor knowledge among French travellers of the risk of acquiring multidrug-resistant bacteria during travel. J Travel Med. 2017;24(1).

65. Nelson W, Harris B. Flies, fingers, fomites, and food. Campylobacteriosis in New Zealand--food-associated rather than food-borne. $N \mathrm{Z} \mathrm{Med}$ J. 2006;119(1240):U2128.

66. Nelson W, Harris B. Can we change the hymn sheet? Campylobacteriosis not just from chicken. N Z Med J. 2006;119(1244):U2299.

67. Poole C. Controls who experienced hypothetical causal intermediates should not be excluded from case-control studies. Am J Epidemiol. 1999;150(6):547-551.

68. Litrup E, Torpdahl M, Nielsen EM. Multilocus sequence typing performed on Campylobacter coli isolates from humans, broilers, pigs and cattle originating in Denmark. J Appl Microbiol. 2007;103(1): 210-218.
Clinical Epidemiology

\section{Publish your work in this journal}

Clinical Epidemiology is an international, peer-reviewed, open access, online journal focusing on disease and drug epidemiology, identification of risk factors and screening procedures to develop optimal preventative initiatives and programs. Specific topics include: diagnosis, prognosis, treatment, screening, prevention, risk factor modification,

Submit your manuscript here: https://www.dovepress.com/clinical-epidemiology-journal

\section{Dovepress}

systematic reviews, risk and safety of medical interventions, epidemiology and biostatistical methods, and evaluation of guidelines, translational medicine, health policies and economic evaluations. The manuscript management system is completely online and includes a very quick and fair peer-review system, which is all easy to use. 